\title{
TREINAMENTO CONCORRENTE NA IMUNIDADE E APTIDÃO FÍSICA DE PACIENTES HIV/AIDS
}

\author{
CONCURRENT TRAINING ON IMMUNITY AND PHYSICAL FITNESS IN HIVIAIDS PATIENTS \\ ENTRENAMIENTO CONCURRENTE EN LA INMUNIDAD Y APTITUD FÍSICA DE PACIENTES VIH/SIDA
}

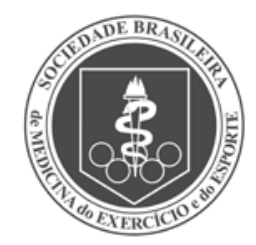

Artigo Original

Original ARTICLE

Artículo Original

\author{
Alexandre Ramos Lazzarotto ${ }^{1,2}$ \\ (Educador físico) \\ Karen Olivia Bazzo ${ }^{3}$ (Biomédica) \\ 1. Unilasalle, Canoas, RS, Brasil. \\ 2. Universidade Federal do Rio \\ Grande do Sul (UFRGS), Porto \\ Alegre, RS, Brasil. \\ 3. Faculdade da Serra Gaúcha (FSG), \\ Caxias do Sul, RS, Brasil.
}

Correspondência: Avenida Vitor Barreto, 2288, Canoas, RS, Brasil. 92010-000. alazzar@terra.com.br

\section{RESUMO}

Introdução: As investigações sobre treinamento físico com pessoas que vivem com HIV/Aids enfatizam os componentes aeróbico, força e concorrente em séries múltiplas. Objetivo: Avaliar o treinamento concorrente com séries simples nos parâmetros imunológico, virológico, cardiorrespiratório e muscular em pacientes com HIV/Aids. Métodos: Séries temporais, com a participação de 6 homens e 1 mulher que faziam uso da TARV. O parâmetro imunológico foi avaliado por citometria de fluxo; o virológico, pelo teste HIV-1 RNA 3.0 (bDNA); o cardiorrespiratório, por meio do protocolo de rampa e o muscular, pelo teste de 15 repetições máximas e número máximo de flexões de tronco em 1 minuto. $O$ treinamento foi realizado três vezes por semana durante 12 semanas, com reavaliações e incrementos mensais. A estatística contemplou valor absoluto, mediana e amplitude e o teste t de Wilcoxon no programa SPSS, versão $20.0(p<0,05)$. Resultados: No parâmetro imunológico, houve aumento do número de linfócitos T CD4+ $(p=0,034)$. No parâmetro virológico, a carga viral em 2 participantes diminuiu (495 para 51 cópias $/ \mathrm{ml}$ e 72 para não detectável $[<50$ cópias/ml]) e 5 mantiveram-na não detectável. No cardiorrespiratório verificou-se aumento do $\mathrm{VO}_{2 \text { máx }}$ absoluto $(p=0,028)$ e da carga máxima de trabalho (Watt) no cicloergômetro $(p=0,015)$. A carga de trabalho aumentou na função muscular de todos os exercícios: voador $(p=0,018)$, roldana alta $(p=0,017)$, pressão de pernas ( $p=0,018)$, roscas bíceps $(p=0,016)$ e tríceps $(p=0,017)$ e número máximo de abdominais $(p=0,018)$. Conclusão: $O$ treinamento melhorou os parâmetros cardiorrespiratório e muscular e não causou efeitos deletérios nos parâmetros imunológico e aumento na carga viral.

Descritores: HIV; síndrome de imunodeficiência adquirida; atividade física.

\section{ABSTRACT}

Introduction: Investigations of physical training with people living with HIV/Aids emphasize the aerobic, strength and concurrent components in multiple sets. Objective: To evaluate the concurrent training with single sets in immune, virological, cardiorespiratory, and muscular parameters in patients with HIV/Aids. Methods: Time series, with the participation of six men and one woman who used HAART. The immune parameter was assessed by flow cytometry, the virological, by the HIV-1 RNA 3.0 (bDNA) assay, the cardiopulmonary through the ramp protocol and the muscular parameter by the 15-repetition maximum and the maximum number of abdominal exercises within 1 minute. The training was performed three times a week for 12 weeks with monthly increments and reevaluations. The statistics included absolute value, median and range and the Wilcoxon $t$ test using SPSS, version $20.0(p<0.05)$. Results: In the immunological parameter, the number of CD4+ Tlymphocytes increased ( $p=0.034$ ). In the virological parameter, the viral load decreased in 2 participants ( 495 for 51 copies $/ \mathrm{ml}$ and 72 non-detectable $[<50$ copies/ml]) and 5 maintained a non-detectable viral load. In the cardiorespiratory parameter there was an increase in the absolute VO2 max $(p=0.028)$ and maximum workload (Watt) in the cycloergometer $(p=0.015)$. The workload increased in muscular function of all exercises assessed: peck deck $(p=0.018)$, latissimus dorsi pull down ( $p=0.017)$, leg press ( $p=0.018)$, arm curl ( $p=0.016$ ) and triceps extension ( $p=0.017$ ) and maximum number of abdominal exercises in 1 minute ( $p=0.018$ ). Conclusion: The training improved cardiopulmonary and muscular parameters and caused no deleterious effects on immune parameter or increase in viral load.

Keywords: HIV; acquired immunodeficiency syndrome; physical activity.

\section{RESUMEN}

Introducción: Las investigaciones sobre entrenamiento físico con personas que viven con VIH/Sida enfatizan los componentes aeróbico, fuerza y concurrente en series múltiples. Objetivo: Evaluar el entrenamiento concurrente con series simples en los parámetros inmunológico, virológico, cardiorrespiratorio y muscular en pacientes con VIH/Sida. Métodos: Series temporales, con la participación de 6 hombres y 1 mujer que hacían uso de TARV. El parámetro inmunológico fue evaluado por citometría de flujo; el virológico, por el test VIH-1 RNA 3.0 (bDNA); el cardiorrespiratorio, a través del protocolo de rampa y el muscular, por el test de 15 repeticiones máximas y número máximo de flexiones de tronco en 1 minuto. El entrenamiento fue realizado tres veces por semana durante 12 semanas, con reevaluaciones e incrementos mensuales. La estadística contempló valor absoluto, mediana y amplitud y el test $t$ de Wilcoxon en el programa SPSS, versión $20.0(p<0,05)$. Resultados: En el parámetro inmunológico, hubo aumento del número 
de linfocitos TCD4+ ( $p=0,034)$. En el parámetro virológico, la carga viral en 2 participantes disminuyó (495 para 51 copias $/ \mathrm{ml}$ y 72 para no detectable [< 50 copias $/ \mathrm{ml}]$ ) y 5 la mantuvieron no detectable. En el cardiorrespiratorio se verificó aumento del VO2 máx $_{\text {absoluto }}(p=0,028)$ y de la carga máxima de trabajo (Watt) en el cicloergómetro $(p=0,015)$. La carga de trabajo aumentó en la función muscular de todos los ejercicios: peck deck ( $p=0,018)$, polea alta $(p=0,017)$, presión de piernas $(p=0,018)$, roscas bíceps $(p=0,016)$ y tríceps $(p=0,017)$ y número máximo de abdominales $(p=0,018)$. Conclusión: El entrenamiento mejoró los parámetros cardiorrespiratorio y muscular y no causó efectos perjudiciales en los parámetros inmunológico y aumento en la carga viral.

Descriptores: VIH; síndrome de inmunodeficiencia adquirida; actividad física.

\section{INTRODUÇÃO}

A síndrome da imunodeficiência adquirida (Aids) é a manifestação clínica avançada de umprocesso de imunodeficiência causado pelo vírus da imunodeficiência humana (HIV), que é transmitido pelas vias sexual, parenteral e vertical ${ }^{1,2}$.

A principal característica do processo infeccioso é a supressão exacerbada da imunidade mediada por células T, fazendo com que os indivíduos fiquem suscetíveis às infecções oportunistas, neoplasias secundárias e doenças neurológicas, que, se não forem combatidas, o conduzirão inevitavelmente ao óbito ${ }^{2-4}$.

Estima-se mundialmente que $0,8 \%$ dos adultos, com idades entre 15 e 49 anos, aproximadamente de 35 milhões, vivem com HIV/Aids 5 . No Brasil, a prevalência decorresponde a 0,4\% da população (734 mil) 6 .

A Terapia Antirretroviral Combinada (TARV), que começou em 1996 com a introdução dos inibidores de protease (IP), proporcionou a diminuição significativa da viremia e, como consequência, a recuperação imunológica, reduzindo a morbimortalidade e gerando o aumento da expectativa de vida de pessoas vivendo com HIV/ Aids (PVHA $)^{2,7}$. No mundo, em 2014, 14,9 milhões de PVHA estavam recebendo a TARV ${ }^{7}$. No Brasil, dos 734 mil casos de Aids, 400 mil estão em tratamento antirretroviral ${ }^{8}$.

A partir da cronicidade da Aids, o desenvolvimento de estratégias terapêuticas que possam contribuir para a melhoria da aptidão física relacionada à saúde de $\mathrm{PVHA}$, sem comprometimento da resposta imunológica, tornou-se um desafio para os profissionais de saúde.

Estudos de treinamento concorrente, ou seja, a combinação de componentes aeróbio e de força na mesma sessão de treino ${ }^{9}$, são escassos, e o componente muscular na expressiva maioria dos trabalhos é treinado comséries múltiplas ${ }^{10}$

Considerando a carência na literatura, foi elaborado um estudo com o objetivo de avaliar o treinamento concorrente com séries simples nos parâmetros imunológico, virológico, cardiorrespiratório e muscular de PVHA em uso de TARV.

\section{MATERIAIS E MÉTODOS}

O delineamento do estudo foi séries temporais. Os participantes foram portadores do HIV/Aids em uso de TARV oriundos de serviços especializados em HIV/Aids da cidade de Porto Alegre, RS, Brasil; sendo convidados a assinar o Termo de Consentimento Livre e Esclarecido. O projeto foi aprovado pelo Comitê de Ética em Pesquisa do Hospital de Clínicas de Porto Alegre sob o protocolo de número 05-591.

A amostra foi selecionada por processo consecutivo de acordo com os seguintes critérios: indivíduos de ambos os sexos clinicamente estáveis, com idades entre 18 a 50 anos, com TCD4+igual ou maior que 200 células/mm3, não-fumantes, não-alcoolistas, em uso de TARVe sem mudança no esquema terapêutico por um período mínimo de três meses e, também, sem a prática de treinamento físico por um período mínimo de seis meses. A análise estatística contemplou valor absoluto, mediana e amplitude e o teste $t$ de Wilcoxon no programa SPSS, versão 20.0 ( $p<0,05)$. A Tabela 1 apresenta as principais variáveis, técnicas e locais de realização.

Os procedimentos foram organizados em anamnese, exames de sangue, avaliações cardiorrespiratórias e musculares e programa de treinamento. As coletas foram realizadas antes da primeira (1a Avaliação) e após a trigésima sexta sessão de treinamento (4a Avaliação). Considerando a alteração da imunidade decorrente do efeito agudo do treinamento, as coletas aconteceram 48 horas após as sessões.

Para a contagem de T CD4+, T CD8+ e carga viral coletou-se $8 \mathrm{~mL}$ de sangue na veia mediana do cotovelo de cada participante.

A avaliação cardiorrespiratória consistiu na ergoespirometria no Protocolo de Rampa em cicloergômetro. A determinação do $\mathrm{VO}_{2 \text { máx }}$ foi obtida através do maior valor no transcorrer do teste ergoespirométrico ${ }^{11}$, realizada a partir do equipamento de ergoespirometria Medgraphics Cardiorespiratory Diagnostic Systems, modelo MGC/ CPX-D, USA (software Breeze 3.06). No dia da avaliação, o referido aparelho de ergoespirometria foi ligado $1 \mathrm{~h}$ antes dela, para aquecimento e estabilização das células analisadoras dos gases. Concluída esta etapa, procedeu-se a calibração do equipamento. Posteriormente, foi iniciada a avaliação.

Inicialmente foram coletados os dados referentes à estatura e massa corporal total do participante. Ao término desta coleta, ele foi orientado na realização de uma sessão de alongamentos, sendo logo em seguida colocados os sensores de frequência cardíaca do eletrocardiógrafo da marca FUNBEC, BRA no seu tórax e ajustado o bocal de coleta de gases

Tabela 1. Principais variáveis, técnicas e locais de realização.

\begin{tabular}{|c|c|c|}
\hline Principais Variáveis & Técnicas & Locais de Realização \\
\hline \multirow{2}{*}{$\begin{array}{c}\text { T CD4+, T CD8+ e relação } \\
\text { T CD4+, T CD8+ (4mL) }\end{array}$} & Citometria de Fluxo & \multirow{4}{*}{$\begin{array}{l}\text { Seção de Virologia do } \\
\text { IPB-LACEN/RS }\end{array}$} \\
\hline & $\begin{array}{c}\text { Equipamento: Sistema BD } \\
\text { FACSCalibur }^{\mathrm{TM}}\end{array}$ & \\
\hline \multirow{2}{*}{ Carga viral (4mL) } & $\begin{array}{l}\text { VERSANT HIV-1 RNA } \\
3.0 \text { Assay (bDNA) }\end{array}$ & \\
\hline & $\begin{array}{l}\text { Equipamento: Analyzer } \\
\text { Quantiplex System } 340\end{array}$ & \\
\hline $\mathrm{VO}_{2 \text { pico }}$ relativo & \multirow{4}{*}{$\begin{array}{l}\text { Protocolo de Rampa } \\
\text { Equipamento: Medgraphics } \\
\text { Cardiorespiratory Diagnostic } \\
\text { Systems, modelo MGC/CPX-D, } \\
\text { USA (software Breeze 3.06) }\end{array}$} & \multirow{4}{*}{$\begin{array}{l}\text { Laboratórios de } \\
\text { Fisiologia e Bioquímica }\end{array}$} \\
\hline $\mathrm{VO}_{2 \text { pico }}$ absoluto & & \\
\hline Watt & & \\
\hline Massa corporal total & & \\
\hline \multirow{2}{*}{$\begin{array}{l}\text { Função muscular nos } \\
\text { exercícios voador, roldana } \\
\text { alta, pressão de pernas, } \\
\text { roscas bíceps e tríceps } \\
\text { e abdominal }\end{array}$} & $\begin{array}{c}\text { Teste de } 15 \text { Repetições } \\
\text { Máximas (15 RM) }\end{array}$ & \multirow[b]{2}{*}{ Sala de Musculação } \\
\hline & $\begin{array}{l}\text { Número Máximo de } \\
\text { Abdominais em } 1 \text { Minuto } \\
\text { Equipamento: módulos da } \\
\text { marca World, halteres } \\
\text { e colchonetes. }\end{array}$ & \\
\hline
\end{tabular}


(conectado ao ergoespirômetro) ao rosto e cabeça. Finalizado o ajuste, o participante realizou a adaptação ao cicloergômetro, com frenagem eletromagnética da marca The Byke, da Cybex, USA, na velocidade mínima com OWatt $(W)$, seguida de um repouso no próprio cicloergômetro durante 2 minutos.

A partir do $3^{\circ}$ minuto, o participante iniciou a pedalar na intensidade de $25 \mathrm{~W}$, ocorrendo então, o incremento de $25 \mathrm{~W} /$ minuto até o tempo máximo de 12 minutos. A cadência de pedalada foi mantida constante entre 60 e 90 rotações por minuto (rpm). Quando o participante atingiu o seu limite máximo de resistência no Protocolo, ele iniciou a fase de recuperação, que consistiu na diminuição gradual da intensidade da velocidade do cicloergômetro até finalizá-lo. A interrupção da avaliação ocorreu quando o participante solicitou, a cadência não foi mantida acima de 60 (rpm) ou quando não existiu um platô na curva de $\mathrm{VO}^{12}$.

Posteriormente à recuperação, o participante realizou uma sessão de alongamentos sob a orientação do pesquisador ou alguém da sua equipe.

A avaliação muscular da força de resistência foi composta pelo teste de 15 Repetições Máximas (RM) nos seguintes exercícios: voador, roldana alta, pressão de pernas, rosca bíceps e rosca tríceps. Para avaliar a resistência do abdome, denominada de exercício abdominal foi realizado o teste que consistiu em executar o maior número possível de flexões de tronco durante 1 minuto.

A velocidade de execução (cadência) dos exercícios voador, roldana alta, pressão de pernas, rosca bíceps e rosca tríceps foi controlada nas fases concêntrica (1 segundo) e excêntrica (2 segundos) durante as avaliações ${ }^{13}$ e os participantes foram orientados a manterem a mesma cadência durante o treinamento.

O treinamento foi realizado em cicloergômetros da marca Movement, modelo BM 2700, módulos de musculação, halteres e colchonetes, na frequência de 3 sessões por semana (12 semanas: 36 sessões), observando-se o intervalo entre 24 e 48 horas nas sessões. A sessão de treinamento foi composta pelos seguintes componentes e tempo de realização: alongamentos (5 minutos), aeróbio (20 minutos), força de resistência (10 minutos) e alongamentos (5 minutos).

Para a determinação da intensidade do treinamento aeróbio observou-se o consumo de oxigênio do participante obtido no protocolo de rampa (de acordo com o percentual correspondente ao número da avaliação: $1^{a}, 2^{a}$, $3^{a}$ ou $4^{a}$ ) e se adequou posteriormente para uma intensidade constante no cicloergômetro, monitorada pela frequência cardíaca. A intensidade individual do treinamento aeróbio foi monitorada pela frequência cardíaca, através de cardiotacômetro da marca Polar, modelo FS1, correspondendo inicialmente a $60 \% \mathrm{VO}_{2 \text { pico, }}$ sendo realizado o incremento na quarta (75\%) e oitava (85\%) semanas e mantido em $85 \%$ até o final da décima segunda semana.

Na força de resistência, a partir da carga obtida no teste de 15 RM, foi desenvolvido o treinamento em séries simples de 15 repetições máximas para os exercícios voador, roldana alta, pressão de pernas, roscas bíceps e tríceps. O abdome foi treinado a uma intensidade de $50 \%$ do número de máximo de repetições obtido no teste de flexão de tronco.

\section{RESULTADOS}

A Tabela 2 descreve as características clínicas dos 7 participantes do estudo. Os resultados da Tabela 3 estão expressos em mediana e amplitude.

No parâmetro virológico ocorreu a diminuição da carga viral em 2 participantes (495 para 51 cópias/mm3 e 72 para indetectável-(<50 cópias/mm3) e 5 a mantiveram indetectável.
Tabela 2. Descrição clínica dos participantes.

\begin{tabular}{|c|c|c|}
\hline Variáveis & \multicolumn{2}{|c|}{ Resultados } \\
\hline Sexo & Masculino - 6 & Feminino - 1 \\
\hline Idade em anos (mediana e amplitude) & \multicolumn{2}{|c|}{$42(29-48)$} \\
\hline $\begin{array}{l}\text { Diagnóstico do HIV em anos } \\
\text { (mediana e amplitude) }\end{array}$ & \multicolumn{2}{|c|}{$10(0,6-12)$} \\
\hline \multicolumn{3}{|l|}{ Esquema Terapêutico da TARV } \\
\hline 2 ITRN + 1IP & \multicolumn{2}{|c|}{4} \\
\hline 2ITRN + 1ITRNN & \multicolumn{2}{|c|}{2} \\
\hline 1ITRNN & \multicolumn{2}{|c|}{1} \\
\hline Tempo de TARV em anos (mediana e amplitude) & \multicolumn{2}{|c|}{$9(0,1-11)$} \\
\hline
\end{tabular}

Transcriptase Reversa Não-Análogo de Nucleosídeo - IP = Inibidor da Protease.

Tabela 3. Comparação dos parâmetros entre a $1^{\circ}$ e $4^{\circ}$ avaliação.

\begin{tabular}{|c|c|c|c|}
\hline Parâmetros & $1^{\circ}$ Avaliação & $4^{\circ}$ Avaliação & $p<0.05$ \\
\hline \multicolumn{4}{|c|}{ Imunológico } \\
\hline TCD4 + & $428(230-614)$ & $573(278-700)$ & $p=0,034$ \\
\hline $\mathrm{TCD} 8+$ & $774(441-987)$ & $919(445-1438)$ & $p=0,310$ \\
\hline $\mathrm{TCD} 4+/ \mathrm{T} \mathrm{CD8+}$ & $0,55(0,39-0,76)$ & $0,63(0,44-0,75)$ & $p=0,150$ \\
\hline \multicolumn{4}{|c|}{ Cardiorrespiratório } \\
\hline $\mathrm{VO}_{2 \text { pico }}$ relativo & $28,4(23,8-42,6)$ & $29,3(28,2-40,6)$ & $p=0,128$ \\
\hline $\mathrm{VO}_{2 \text { pico }}$ absoluto & $1778(1348-2246)$ & 2039(1469-2215) & $p=0,028$ \\
\hline Watt & $150(100-175)$ & $200(125-225)$ & $p=0,015$ \\
\hline Massa Corporal Total (kg) & $63,7(38,6-73,2)$ & $63,6(39,3-73,8)$ & $p=0,249$ \\
\hline \multicolumn{4}{|c|}{ Muscular } \\
\hline Voador & $20(10-20)$ & $35(13-60)$ & $p=0,018$ \\
\hline Roldana Alta & $20(10-35)$ & $40(23-55)$ & $p=0,017$ \\
\hline Pressão de pernas & $40(30-70)$ & $100(70-180)$ & $p=0,018$ \\
\hline Rosca Biceps & $4(2-5)$ & $8(4-9)$ & $p=0,016$ \\
\hline RoscaTríceps & $17(10-25)$ & $35(15-45)$ & $p=0,017$ \\
\hline Abdome* & $40(30-50)$ & $60(51-69)$ & $p=0,018$ \\
\hline
\end{tabular}

Unidades: $\mathrm{VO}_{2 \text { max }}$ relativo (mL.Kg-1.min-1); $\mathrm{VO}_{2 \max }$ absoluto(mL.min-1); Massa corporal total (kg); carga em Kg $\mathrm{e}^{*}$ número de repetições máximas em 1 minuto.

\section{DISCUSSÃO}

Neste estudo, o treinamento concorrente com séries simples gerou um aumento significativo no T CD4+, no VO $\mathrm{V}_{2 \text { pico }}$ absoluto, na carga máxima de trabalho no cicloergômetro e na função muscular de todos os exercícios. A carga viral diminuiu em 2 participantes e 5 a mantiveram indetectável. A partir da comparação destes resultados com outros estudos ${ }^{14-19}$ é possível afirmar que:

a. O treinamento concorrente com séries simples não causou efeitos deletérios na resposta imunológica e não aumentou a carga viral.

b. Com o tempo máximo total de 40 minutos por sessão conseguiu-se melhorias nos parâmetros cardiorrespiratório e muscular em 12 semanas ou num período menor de treinamento (muscular); nos quais os treinamentos com séries múltiplas apresentaram resultados semelhantes, porém, no tempo médio de 78 minutos $( \pm 26,8)$ minutos por sessão e/ou num período maior de treinamento: a maioria a partir de 16 semanas.

Nos parâmetros imunológico e virológico, o aumento significativo do TCD4+, que é o marcador prognóstico da progressão da Aids e da sobrevivência dos indivíduos infectados pelo HIV²0, a diferença não significativa de T CD8+ (cuja atividade é citotóxica) e a permanência indetectável ou a diminuição da carga viral nos participantes deste estudo, indicam que o treinamento concorrente com séries simples pode ser uma estratégia terapêutica segura para esses indivíduos. O fato da relação T CD4+/T CD8+ não ter apresentado um aumento significativo, mesmo com os resultados positivos destas variáveis isoladas, pode ser explicado pela inversão entre o número de T CD4+ e T CD8+ que se inicia no período assintomático na maioria dos indivíduos infectados pelo HIV. A hipótese de overtraining 
(sobretreinamento ${ }^{21}$ que, no caso de indivíduos infetados pelo HIV, poderia exacerbar a sua deficiência imunológica através do exercício físico, não foi evidenciada neste estudo.

A influência do exercício físico na resposta imunológica já tem sido reportada em outros estudos ${ }^{14-19}$, porém, sem diferenças significativas. Nos mesmos trabalhos citados anteriormente e que contemplaram a carga viral, não houve diminuição significativa em 5 deles, podendo estes resultados serem atribuídos à relação inversamente proporcional entre a carga viral e a resposta imunológica, de acordo com a fisiopatogenia da infecção pelo HIV. A exceção é o trabalho de Grinspoon et al. ${ }^{18}$ que, mesmo não ocorrendo o aumento significativo no T CD4+ nos grupos controle e experimental, a carga viral diminui significativamente neste grupo.

No parâmetro cardiorrespiratório não houve aumento significativo na massa corporal total e no $\mathrm{VO}_{2 \text { pico }}$ relativo. A explicação para estes resultados consiste que, a maioria dos participantes apresentou a variação positiva máxima de $1 \mathrm{Kg}$ na sua massa corporal total (um deles a manteve igual ao início do treinamento), indicando que esta variação não foi suficiente para garantir o aumento significativo no $\mathrm{VO}_{2 \text { pico }}$ relativo, mesmo com o aumento significativo do $\mathrm{VO}_{2 \text { pico }}$ absoluto. Provavelmente, os participantes diminuíram a massa gorda e aumentaram a muscular, ou seja, substituíram uma pela outra sem grandes variações positivas na massa corporal. Corroborando esta explicação, tem-se o aumento significativo na carga máxima de trabalho no cicloergômetro e no $\mathrm{VO}_{2 \text { pico }}$ absoluto. A melhoria do parâmetro cardiorrespiratório está em conformidade com os estudos de Dolanet al. ${ }^{14}$, Driscoll et al. ${ }^{15}$, Engelson et al. ${ }^{16}$, Fillipas et al. ${ }^{17}$ e Rojas et al. ${ }^{19}$, porém, no trabalho de Robinson et al.22, que utilizaram o treinamento concorrente com séries simples, não houve aumento no $\mathrm{VO}_{2 \text { máx }}$ relativo e os autores não mencionaram os resultados do $\mathrm{VO}_{2 \text { máx }}$ absoluto e nem o T CD4+ e a carga viral (pós menos pré-intervenção), dificultando uma análise mais detalhada dos seus resultados.

No parâmetro muscular, além da melhoria da força de resistência em todos os exercícios, o treinamento concorrente com séries simples proporcionou a diminuição do tempo de execução por exercício e de treinamento, evitando-se desta forma a exposição do participante a um estresse físico desnecessário, que poderia resultar em lesões musculoesqueléticas. Nos estudos com séries múltiplas, os aumentos significativos da força em todos os exercícios ${ }^{14,16,19}$ ou da massa muscular ${ }^{18}$ foram citados apenas após o período de treinamento; e nos trabalhos de Grinspoon et al. ${ }^{18}$ e Driscoll et al. ${ }^{15}$ este aumento não aconteceu em todos os exercícios. O estudo de Fillipaset al. ${ }^{17}$ não menciona os resultados pós menos pré-intervenção na força e na massa muscular. No estudo de Robinson et al. ${ }^{22}$, o aumento da força aconteceu após as 16 semanas de treinamento nos 7 exercícios avaliados.

Os resultados positivos deste estudo merecem cautela, pois ele apresenta como principal limitação a ausência de um grupo controle, que poderia contribuir para uma melhor explicação destes resultados, porém, esse é o primeiro trabalho com treinamento concorrente com séries simples que evidencia o aumento da resposta imunológica e a diminuição da carga viral, concomitante à melhoria da aptidão física relacionada à saúde (parâmetros cardiorrespiratório e muscular).

\section{CONCLUSÃO}

O treinamento concorrente com séries simples demonstrou ser uma estratégia terapêutica não medicamentosa efetiva na melhoria dos parâmetros cardiorrespiratório e muscular e não causou efeitos deletérios no imunológico eaumento na carga viral. Sugere-se que este treinamento seja investigado com um tamanho amostral maior e com o delineamento de ensaio clínico randomizado.

\section{AGRADECIMENTOS}

Os autores agradecem ao CNPq (Conselho Nacional de Desenvolvimento Tecnológico) pelo suporte financeiro.

Todos os autores declararam não haver qualquer potencial conflito de interesses referente a este artigo.

CONTRIBUIÇÕES DOS AUTORES: ARL (0000-0002-4606-7476)* elaborou o projeto, participou da coleta, da analise de dados e da redação final do manuscrito e KOB (0000-0002-4680-2813)* realizou a revisão final do artigo. *Número ORCID (Open Researcher and Contributor ID).

\section{REFERÊNCIAS}

1. UNAids. Report on the global Aids epidemic, 2012 [acesso em 2015 jun 15]. Disponivel em: http://www.unAids.org/sites/default/files/media_asset/20121120_UNAids_Global_Report_2012_with_annexes_en_1.pdf.

2. Centers for Disease Control and Prevention.HIV/Aids basics [acesso em 2015 jun15]. Disponível em: http://www.cdc.gov/hiv/basics/index.htm

3. Borges IK, Lima JE, Milanez PAO, Bernardes SS, Felipe I, Costa IC, et al. Participação de células T regulatórias (Tregs) na imunopatogênese da infecção pelo vírus da imunodeficiência humana 1 (HIV-1). Semin Cienc Biol Saude. 2010;31(2):169-78.

4. Asboe D, Aitken C, Boffito M, Booth C, Cane P, Fakoya A, et al. British HIV Association guidelines for the routine investigation and monitoring of adult HIV-1-infected individuals. HIV Med. 2011;13(1):1-44

5. WHO. World Health Organization. HIV/Aids. Key Facts [acesso em 201516 jun]. Disponivel em: http:// www.who.int/mediacentre/factsheets/fs360/en/

6. Brasil. Ministério da Saúde. Departamento de DST, Aids e Hepatites Virais. Boletim epidemiológico. [Acesso em: 15/jun/2015]. Disponível em: http://www.Aids.gov.br

7. World Health Organization. HIV/Aids. Treatment and care[acesso em 2015 jun 16]. Disponível em: http://www.who.int/hiv/topics/treatment/en/

8. Brasil. Ministério da Saúde. Departamento de DST, Aids e Hepatites Virais. Protocolo clínico e diretrizes terapêuticas para manejo da infecção pelo HIV em adultos. Boletim Epidemiológico 2014 [acesso em 2015 jul 30]. Disponível em: http://www.Aids.gov.br/pcdt/protocolo-clinico.

9. Guedes DP. Treinamento concorrente-abordagem atual. Centro de Estudos de Fisiologia do Exercício. São Paulo: Unifesp; 2004

10. Farinatti PT, Borges JP, Gomes RD, Lima D, Fleck SJ. Effects of a supervised exercise program on the physical fitness and immunological function of HIV-infected patients. J Sports Med Phys Fitness. 2010;50(4):511-8,

11. Brito FS, Vilas-Boas F, Castro I, Oliveira JA, Guimarães JI, Stein R, et al. II Diretrizes da Sociedade Brasileira de Cardiologia sobre teste ergométrico.Arq Bras Cardiol. 2002;78(1):1-17.

12. Howley ET, Bassett DR, Welch HG. Criteria for maximal oxygen uptake: review and commentary. Med Sci Sports Exerc. 1995;27(9):1292-301.
13. Kraemer WJ, Ratamess NA. Fundamentals of resistance training: progression and exercise prescription Med Sci Sports Exerc. 2004;36(4):674-88.

14. Dolan S, Frontera W, Librizzi J, Ljungquist K, Juan S, Dorman R, et al. Effects of a supervised home-based aerobic and progressive resistance training regimen in women infected with human immunodeficiency virus: a randomized trial. Arch Intern Med. 2006;166(11):1225-31.

15. Driscoll SD, Meininger GE, Lareau MT, Dolan SE, Killilea KM, Hadigan CM, et al. Effects of exercise training and metformin on body composition and cardiovascular indices in HIV-infected patients. Aids. 2004;18(3):465-73

16. Engelson ES, Agin D, Kenya S, Werber-Zion G, Luty B, Albu JB, et al. Body composition and metabolic effects of a diet and exercise weight loss regimen on obese, HIV-infected women. Metabolism. 2006;55(10):1327-36.

17. Fillipas S, Oldmeadow LB, Bailey MJ, Cherry CL. A six-month, supervised, aerobic and resistance exercise program improves self-efficacy in people with human immunodeficiency virus: a randomised controlled trial. Aust J Physiother. 2006;52(3):185-90.

18. Grinspoon S, Corcoran C, Parlman K, Costello M, Rosenthal D, Anderson E, et al. Effects of testosterone and progressive resistance training in eugonadal men with Aids wasting. A randomized, controlledtrial. Ann Intern Med. 2000;133(5):348-55.

19. Rojas R, Schlicht W, Hautzinger M. Exercise Psychology Effects of Exercise Training on Quality of Life, Psychological Well-Being, Immune Status, and Cardiopulmonary Fitness in an HIV-1 Positive Population. J Sport Exerc Psychol. 2003;25(4):440-55.

20. Phillips NA, Lundgren JD. The CD4 lymphocyte count and risk of clinical progression.Curr Opin HIV Aids. 2006;1(1):43-9.

21. Paulo AC, Souza EO, Laurentino G, Ugrinowitsch C, Tricoli V. Efeito do treinamentoconcorrente no desenvolvimento da força motora e da resistência aeróbia. Rev Mackenzie Educ Fís Esporte. 2005;4(4):145-54.

22. Robinson FP, Quinn LT, Rimmer JH. Effects of high-intensity endurance and resistance exercise on HIV metabolic abnormalities: a pilot study. Biol Res Nurs. 2007;8(3):177-85. 